\title{
Quotation and Plagiarism between the Copyright Law and Academic Ethics
}

\author{
Wei LIU \\ Library, Zhongnan University of Economics and Law, Wuhan, China \\ Distinct addresses: 182\# Nanhu Avenue, Wuhan 430073, P.R.China \\ 875912010@qq.com
}

Keywords: Copyright, Fair Use, Plagiarism, Quotation, Academic Ethics

\begin{abstract}
The purposes of this paper is introduce the quotation and plagiarism of United States Copyright Law, the international convention and China Copyright Law. China's current copyright law for plagiarism is too abstract to judge, court practice and academic circles have different standards. By comparing the definition of quotation and plagiarism in court practice and academic circles, hope that academic researchers can grasp the difference between two, and to avoid violating of academic ethics and copyright law.
\end{abstract}

\section{Introduction}

It is important for paper quotation in the academic field. The citation is not only to respect for copyright infringement, but also conducive to academic inheritance and development of culture. Picasso once said "Good artists copy, great artists steal”, but improper references will become plagiarism or even illegal. In recent years, with the rapid development of the Internet, and big bang growth in information, citing other people's work is also more convenient, thus causing a lot of plagiarism scandal in the domestic and foreign academic circles.

August 17, 2014, the Chinese Journal of Journalism and Communication, a major academic journal, said in a public notice that Yu-Yanru, who has doctorate's degree in history from Peking University, had heavily plagiarized another paper in her essay published in seventh issue in 2013.The journal said Yu had translated paragraphs word by word from "Frondeur" Journalism in the 1770s: Theatre Criticism and Radical Politics in the Prerevolutionary French Press, published by Johns Hopkins University Press in the United States. The notice, widely circulated on social media in China, prompted Peking University to revoke her degree in January 2015. Yu took her former college to court demanding reinstate her $\mathrm{PhD}$ degree. Yu sad to the media: whether the article constitutes plagiarism is in doubt. I have absolutely no subjective intent, the error is because I lack of writing experience .One most important evidence is that at the paper beginning i cited the article two times, and annotated the author name. If $\mathrm{i}$ were intentional plagiarism, i should completely hidden in the article [1]

The case has heavily attracted public attention. How to seek balance between academic norms and academic freedom, how to establish reasonable distinction between reference and plagiarism, is the current focus of China's academic circles and legal practice. Through the introduction about "fair use" of United States Copyright Law, the international convention ,China's Copyright Law and the judicial practice, we hope that by comparing the definition of reference and plagiarism in the legal and academic circles, academic researchers can grasp the difference between the two, and avoid violating of academic ethics and copyright law.

\section{The Cognizance of "Fair Use"}

\section{United States Copyright Law}

"Copyright is a kind of intellectual property rights, it is created by human mental wisdom, this kind of spirit creates the value of the property and form right which is protected by law". [2] Copyright law is not simply to protect the copyright owner, also protect the development of social 
culture. On the one hand, Copyright law granted author to safeguard their rights, on the other hand, appropriate limit to author rights, allowing others fair use of the work within the bounds of the law, to promote cultural development and social progress. Reconcile personal interests and public interests balance method is the principle of "fair use". The revised copyright law in 1974, stated in the fair use of the principle, to become one of the main principles of copyright law in the United States, also become an important standard of judging infringement or not. Copyright law of the United States 107th Provisions of the four standards for "fair use" [3] :(1) the purpose and character of the use, including whether such use is of a commercial nature or is for nonprofit educational purposes;(2) the nature of the copyrighted work;(3) the amount and substantiality of the portion used in relation to the copyrighted work as a whole; and (4) the effect of the use upon the potential market for or value of the copyrighted work.

\section{International Convention}

In the world, the earliest and most important Copyright Convention is Berne Convention .In this law, Article 10 define free uses[4] :

(1) It shall be permissible to make quotations from a work which has already been lawfully made available to the public, provided that their making is compatible with fair practice, and their extent does not exceed that justified by the purpose, including quotations from newspaper articles and periodicals in the form of press summaries.(2) It shall be a matter for legislation in the countries of the Union, and for special agreements existing or to be concluded between them, to permit the utilization, to the extent justified by the purpose, of literary or artistic works by way of illustration in publications, broadcasts or sound or visual recordings for teaching, provided such utilization is compatible with fair practice.(3) Where use is made of works in accordance with the preceding paragraphs of this Article, mention shall be made of the source, and of the name of the author if it appears thereon.

\section{Copyright Law of China}

According to Copyright Law of China (2010 Amendment),Article 22 :In the following cases, a work may be exploited without the permission from, and without payment of remuneration to, the copyright owner, provided that the name of the author and the title of the work are mentioned and the other rights enjoyed by the copyright owner by virtue of this Law are not infringed upon:(1) use of a published work for the purposes of the user's own private study, research or self-entertainment; appropriate quotation from a published work in one's own work for the purposes of introduction of, or comment on, a work, or demonstration of a point;

\section{Plagiarism Identification}

\section{United States}

"Plagiarism" usually refers to the form of copyright infringement, the concept originated in the United States copyright law, but did not use "plagiarism”, but use the word "copying". In judicial practice, determining Copyright Infringement adopt "access plus substantial similarity" principle.

As regards "access", the plaintiff has the burden of proof to show that the defendant has had access to the plaintiffs work. The burden of proof is met when the plaintiff has produced direct or indirect evidence showing that the defendant has factually had access to or has a reasonable opportunity or reasonable likelihood of access to the plaintiffs work. If the defendant objects to the application of this rule, then the burden of proof will shift to the defendant who must prove that the allegedly infringing work is a result of his/her" independent creation. 'In general, the direct "access" evidence includes reading or viewing the plaintiffs work by the defendant, or the fact that the defendant once worked with the plaintiff. What is "substantial similarity", the rules is that if works impress the general public as basically the same, then it can be determined that they constitute substantial similarity. There are two kinds of judgment method:(1)Quantity.V erbatim copying or exact copying others work most of the content may constitute the essence of the similar 
works;(2)Quality. Quantity is not a decision factor, if the recipient is material and substantial , although the proportion is not much, also constitute a similar substance.

In US judicial practice, courts often divide the issue into two levels: First, there is a determination of copying, second, determination of whether it is illicit copying, "illicit" means the defendant has unlawfully copy the part protected by the copyright law. So, copying is not necessarily illegal, copying is wide than scope of illegal copying.

\section{China}

China's current copyright law and related administrative regulations did not define plagiarism. In the copyright law, "plagiarism" is too abstract and difficult to judge and identification. Relevant administrative rules and regulations are also unable to define the plagiarism. For example: Provisions on the Administration of Students in Regular Institutions of Higher Education (2005) ,Article 54§5: Plagiarism, copying other people's research results, if the circumstances are serious; Measures for the Handling of Acts to Falsify Dissertations (2012) ,Article 3§3:Plagiarism of others' works and academic achievements. Therefore, most people especially the academic scholars unable to define the difference between plagiarism and quotation.

In China's judicial practice, the standard of "access plus substantial similarity" has always been adopted to define plagiarism.

In Sheng Lvweiv. Tianjin Language Institute(2005), The judge ruled that "Plagiarism refers to the copying of other people's thoughts or words, or the works created by others, and don't say the source of the behavior”.[5] In Jiang, Youbov. Zhou Weijun, Jiangsu People Publishing House Co., Ltd (2013), The judge ruled that "first, as a biographical documentary works, with reference to the first hand information is reasonable, but the reference does not mean copying. The author in reference first-hand information, can be expressed in their own way, thus completing certain works, but not necessarily to the original extract; References should be specified in the name of the author, title of the work using the amount of text in a certain range. In this case, Jiang's article neither is signed, nor specify the source and use of nearly 20000 words, the behavior is beyond the scope of fair use".[6]

The law is the minimum moral standard, but it does not represent the requirements of the academic ethics. In the academic level, the definition of plagiarism should be widely defined in legislation and judicial.

For example,<Beijing University Graduate Students Basic Academic Standard, $>$ the article 4, paragraph 2:"unfair means to the works of others or of all or part of the appropriation, quotations from other works could not be annotated and so on plagiarism".< Fudan University academic standard and deal with illegal way >(for Trial Implementation), the article 6:"(1)Plagiarism: others academic point of view, ideas and achievements posing for their own record; unauthorized use of academic information obtained in the peer review or other review.(2) Plagiarism: the others that have been published or unpublished works, does not indicate the source, and as the results of their research using.(3)serious Plagiarism: in their paper, copy part of the works or other achievements in accounted for more than 20\%”.

Taiwan < administrative National Science Council of academic ethics case processing> paragraph 3 of Article 3 points: "plagiarism: refers to invoke other applications, research data and research results did not indicate the source. Indicate the source are serious, is copy. Before the "case of academic ethics approach" (Draft), provided the plagiarism is defined as: "for yourself or others study, using the research data and research results, did not indicate the source. Indicate the source improper, plot, or not properly indicate the source and translation instead of works are plagiarism."Yun -Yangru's paper belongs to this kind of situation, translation instead of works, even she has cited, apparently belonging to plagiarism.

Generally speaking, there are three main forms of plagiarism in academic: Copying other people's works, including without consent and consent (such as others write), and claiming to be their own original;(2) Copied a large number of the original language, and did not make a cite;(3)Tell others views and thoughts in own words, but no mention of the original author and 
source [7]

In practice, some colleges and universities began to use the detection system to define plagiarism. There are developed a lot of the systems on market. But the definition is not consistent, from the perspective of the index, Some universities use a single indicat or, the coincidence of the number of words or coincidence percentage; some universities use a double indicator, that is, the coincidence of the number of words and coincidence percentage. Such as, Shenzhen University provides that copy text is less than $10 \%$, can be directly submitted, copy text ratio is more than $40 \%$, the degree of the application is invalid, six months or a year before this thesis application. ${ }^{[8]}$

But the defects of academic misconduct detection system is actually very obvious, one is that the normal reference usually be misjudgment of plagiarism, the second is that it unable to determine those which only change the individual word or sentence. As for idea plagiarism is more difficult to judge and identified. Some speculators have compiled many strategies to avoid being detected. Many authors have had to spend a lot of extra time, energy and money to deal with detect. Many students before submit the paper in software self-test again, to modify the part of suspected plagiarism .

\section{Difference between Legal and Academic Ethics}

Copyright law on "fare use" is loose than quotation of academic papers, but the copy on the copyright law, is more narrow than the plagiarism of the academic papers. For academic papers, if references did not indicate the source, whatever an article, a paragraph, or a sentence, all constitute plagiarism. Even quoted his own articles (Self-Plagiarism), also may be in violation of academic ethics, but there is no problem in copyright law. The copy of the violation of copyright law, will also constitute academic plagiarism; But academic plagiarism is not in violation of copyright law. Academic ethics requirements are higher than the legal.

Violation of copyright law or academic ethics, may be liable for three: civil liability, criminal liability and administrative responsibility. The civil liability for such remedies as"ceasing the infringements, eliminating the effects of the act, making a public apology or paying compensation for damages, depending on the circumstances"(Copyright Law.art.47 (2010)(P.R.C)). On the Criminal law, for the purpose of making profits, reproducing and distributing a written work," if the amount of illegal gains is relatively large, or if there are other serious circumstances, be sentenced to fixed-term imprisonment of not more than three years or criminal detention and shall also, or shall only, be fined; if the amount of illegal gains is huge or if there are other especially serious circumstances, he shall be sentenced to fixed-term imprisonment of not less than three years but not more than seven years and shall also be fined"(Criminal law, Art. 217, P.R.C).

Administrative punishment, mainly the ministry of education and punishment of the college education regulations, including: lessons research project, and recover the research funding, application of stop recruit graduate students, suspend or cancel the graduate student guidance teachers' qualification and does not grant or revoke degree.[9]

\section{How to Avoid Plagiarism}

\section{Strengthening Academic Ethics Education}

Higher education should Strengthening academic ethics education, students and scholars should understand the citation norms. At present, there are three main types of cite in the academic circles of china: $<$ Standard Specification for Chinese Academic Journal (CD) technology $>$ (CAJ-CD B/T $1-2006),<$ Universities Standard of social science journals $>,<$ Reference rule $>(G B / T$ 7714-2005). etc. But In the field of legal research, there is no uniform standard of legal citation, Publishers and magazines are also different with national standards. Author should pay attention to these details.

In American, there are three main types of cite, include: $<$ The Chicago Manual of Style $>,<M L A$ Style Manual and Guide to Scholarly Publishing $>,<$ Publication Manual of the American Psychological Association>, etc.

In the process of paper writing, it must to do well the literature cited, all references to the work of 
others, be sure to use quotation, to render a complete bibliography .

\section{Make Full Use of the Open Access Journal}

Open access Journal refers to any electronic journals that provide readers or institutions to access, download, copy, print, share, issue or retrieve in a free way .Access Open documents provided by the author or copyright holder is allowed to further copy or transfer. In addition to the rapid and free, author will not need to face the fare use of the dispute or the possible infringement concerns.

\section{References}

[1] http://news.sina.com.cn/s/2015-03-02/140031557807.shtml.

[2] http://news.sina.com.cn/s/2015-03-02/140031557807.shtml.

[3]17 U.S. Code $\S 107$

[4]Berne Conventionfor the Protection of Literary and Artistic Works,(1979),art.10.

[5]Shocked by the academic circles at home and abroad impact of major events,Ma-Qingzhu,et al.ed. China Social Sciences Publishing House,(2007).P:76.

[6] http://www.pkulaw.cn/Case/pfnl_119570177.html?match=Exact,(CLI.C.2129665).

[7]Conlin Neville,The Complete Guide to Referencing and Avoiding Plagiarism,Shanghai education publishing house,(2013).P:28.

[8]The Interim Measures for the examination and the results of the academic misconduct of the graduate degree thesis of Shenzhen University.http://www.szu.edu.cn/view.asp?id=112.

[9] Fudan university academic norms and illegal treatment method (trial), http://www.gs.fudan.edu.cn/6a/b9/c2852a27321/page.htm. 